\title{
Quantitativo de acidentes de trabalho na construção civil de 2015 a 2017 no Brasil
}

A indústria da construção civil historicamente é um dos setores produtivos que apresentam maiores índices de acidentes de trabalho no Brasil. Este fato se deve a exposição a diversos riscos que os trabalhadores do setor estão dispostos diariamente, sendo muitas vezes os acidentes sofridos fatais. Este trabalho buscou analisar quantitativamente os acidentes de trabalho ocorridos no setor da construção civil brasileira entre os anos de 2015 e 2017 , divididos por estados e regiões, e identificou a contribuição do estado do Tocantins e da região Norte no total de acidentes. Para isso foi realizado um levantamento dos dados mais recentes disponibilizados pelo Ministério da Previdência Social. A partir da análise dos dados observou-se que a quantidade de acidentes sofreu reduções sucessivas durante o período analisado, entre as causas desta redução está a crise financeira que provocou uma diminuição na quantidade de empresas e profissionais ativos na construção civil. Por fim, foram propostas medidas preventivas, inclusive com uma cartilha para os trabalhadores, a fim de contribuir com a redução da quantidade de acidentes de trabalho.

Palavras-chave: Quantitativo; Acidente de trabalho; Construção Civil; Cartilha.

\section{Quantitative of work accidents in civil construction from 2015 to 2017 in Brazil}

\begin{abstract}
The construction industry has historically been one of the productive sectors with the highest rates of occupational accidents in Brazil. This fact is due to the exposure to various risks that workers in the sector are willing to deal with on a daily basis, with accidents often being fatal. This work sought to quantitatively analyze occupational accidents that occurred in the Brazilian civil construction sector between the years 2015 and 2017, divided by states and regions, and identified the contribution of the state of Tocantins and the North region in the total of accidents. For this, a survey of the most recent data made available by the Ministry of Social Security was carried out. From the analysis of the data it was observed that the number of accidents suffered successive reductions during the analyzed period, among the causes of this reduction is the financial crisis that caused a decrease in the number of companies and professionals active in the construction industry. Finally, preventive measures were proposed, including a booklet for workers, in order to contribute to reducing the number of accidents at work.
\end{abstract}

Keywords: Quantitative; Work accident; Construction; Booklet.

Topic: Engenharia Organizacional e do Trabalho

Reviewed anonymously in the process of blind peer.
Received: 07/08/2020

Approved: 21/11/2020
Hiago Manoel da Silva (10)

Instituto Tocantinense Presidente Antônio Carlos, Brasil

http://lattes.cnpq.br/4344155438917792

http://orcid.org/0000-0003-2140-2060

hiagomanoeldasilva@gmail.com

José Djair Casado de Assis Junior (iD

Instituto Tocantinense Presidente Antônio Carlos, Brasil

http://lattes.cnpq.br/4023545131498764

http://orcid.org/0000-0001-9433-3997

djairjunior@gmail.com
Referencing this:

SILVA, H. M.; ASSIS JÚNIOR, J. D. C.. Quantitativo de acidentes de trabalho na construção civil de 2015 a 2017 no Brasil. Engineering Sciences, v.8, n.3, p.65-73, 2020. DOI:

http://doi.org/10.6008/CBPC2318-3055.2020.003.0007 


\section{INTRODUÇÃO}

Os acidentes de trabalho ainda são uma realidade cruel e constante no Brasil e no Mundo, tendo na construção civil uma parcela significativa destes acidentes. Inúmeras são as causas que fazem deste setor um dos mais expressivos em relação ao número de acidentes e doenças ocupacionais, pois os trabalhadores estão expostos diariamente a vários riscos no seu ambiente de trabalho, sejam eles: físicos, químicos, biológicos, ergonômicos e/ou acidentais.

Entre as causas pode-se citar a falta de qualificação dos trabalhadores, falta ou ineficácia de treinamento, cujos riscos são elevados, a exemplo de trabalhos em altura, manuseio de ferramentas perigosas, ambiente de trabalho insalubre e exposto às intempéries, falta de fiscalização no canteiro de obras, não cumprimento das legislações de segurança e saúde do trabalhador, entre outros fatores.

As consequências destes acidentes são muitas e reflete nos trabalhadores, nos familiares, nas empresas e na economia. Para evitar estes acidentes e suas implicações é preciso investir em prevenção, e para isso é fundamental um esforço conjunto empregadores, empregados e o poder público, cada player atuando nos campos que lhes competem.

As medidas de segurança devem ser adequadas e eficazes, implantadas a partir de um sistema de gestão apropriado e que obedeçam às legislações aplicáveis que devem ser constantemente revisadas para se adequarem às tecnologias que surgem cada vez mais rapidamente.

Este trabalho analisou o quantitativo de acidentes de trabalho ocorridos no Brasil na indústria da construção civil comparando o estado do Tocantins e da Região Norte com o restante do país no triênio 2015, 2016 e 2017, que são os dados mais atualizados do Ministério da Previdência Social, disponibilizados no site e no Anuário Estatístico de Acidentes de Trabalho (AEAT).

O quantitativo dos acidentes de trabalho na indústria da construção entre 2015 e 2017 no Brasil teve decréscimos sucessivos, porém ainda constitui números expressivos e que necessitam de atenção por parte de todos, a fim de reduzi-los.

Ao analisar a quantidade de trabalhadores ativos na construção civil pode-se deduzir uma proporcionalidade entre estes e o número de acidentes. No Brasil, em 2015 houve 38.926 acidentes e havia 2.439.997 trabalhadores ativos na construção civil; em 2016 reduziu para 2.002 .983 pessoas ocupadas e a quantidade de acidentes reduziu para 33.063; em 2017 os números continuaram diminuindo foram 1.909.293 trabalhadores e 26.959 acidentes. Logo, é possível afirmar que quanto menos trabalhadores ativos menor é a quantidade de acidentes.

Também há outras medidas que contribuem para reduzir estes índices, como por exemplo a aplicação das normas de segurança e a fiscalização pelos órgãos competentes.

Desta forma foi possível identificar quais as variáveis se correlacionam com a quantidade de acidentes e propor medidas assertivas para que haja em curto e médio prazo uma redução dos mesmos. Para tal, foi proposta uma cartilha com linguagem acessível para os trabalhadores da construção civil, contendo recomendações preventivas para combater os acidentes de trabalho e as doenças ocupacionais no setor da 
construção civil.

\section{METODOLOGIA}

Para o desenvolvimento deste trabalho foi realizado o levantamento de dados através do sítio do Ministério da Previdência Social ${ }^{1}$, analisando os dados mais atualizados do triênio 2015-2017.

Os dados consolidados por estado e região do Brasil com a análise do total de acidentes de trabalho correspondentes às atividades da indústria da construção civil agrupadas nos códigos Classificação Nacional de Atividades Econômicas - CNAE $^{2} 2.0$ seção $F$, divisões 41 - Construção de Edifícios, 42 - Obras de Infraestrutura e 43 - Serviços Especializados para construção.

As descrições dos CNAES de cada divisão estão expostas abaixo: Divisão 41 - Incorporação de empreendimentos imobiliários e construção de edifícios; Divisão 42 - Construção de rodovias, ferrovias, obras urbanas e obras-de-arte especiais; obras de infraestrutura para energia elétrica, telecomunicações, água, esgoto e transporte por dutos; e a construção de outras obras de infraestrutura, como obras portuárias, marítimas e fluviais, e montagem de instalações industriais e de estruturas metálicas; Divisão 43 -Execução de partes de edifícios ou obras de infraestrutura, entre elas, demolição e preparação do terreno para construção, instalações elétricas, hidráulicas e outras instalações em construções, e as obras de acabamento.

O quantitativo levantado corresponde ao total de acidentes, que compreendem aos acidentes com Comunicação de Acidentes do Trabalho - CAT registrada, sendo o motivo típico, trajeto ou doença de trabalho; e sem CAT registrada.

Após o levantamento dos dados, os mesmos foram agrupados em tabelas e gráficos, comparando os quantitativos entre os estados e regiões, com enfoque para o estado do Tocantins e região Norte. Para uma melhor análise dos dados foi realizada uma pesquisa bibliográfica abordando temáticas relevantes que auxiliaram na interpretação e compreensão destes quantitativos, além de abordar possíveis soluções para a problemática.

Com o intuito de minimizar e evitar os acidentes de trabalho na construção civil, foi elaborada uma cartilha para os trabalhadores, abordando as medidas de segurança que devem ser seguidas por eles para a prevenção destes acidentes.

\section{RESULTADOS E DISCUSSÃO}

O quantitativo dos acidentes de trabalho na construção civil foi retirado do site do Ministério da Previdência Social, por meio do acesso ao aplicativo AEAT INFOLOGO, onde foi verificado o anuário estatístico de acidentes de trabalho.

Os dados se referem aos valores totais dos acidentes de trabalho por estado e por região, correspondentes aos códigos CNAE 2.0 seção F, divisões 41 - Construção de Edifícios, 42 - Obras de

\footnotetext{
1 dardo 10.0.93 - AEAT InfoLogo

${ }^{2}$ Conforme Ministério da Fazenda (2017) a CNAE é a classificação oficialmente adotada pelo Sistema Estatístico Nacional e pelos órgãos federais gestores de registros administrativos.
} 
Infraestrutura e 43 - Serviços Especializados para construção, conforme tabela 01.

Tabela 1: Total de acidentes de trabalho na construção civil por estado e região entre 2015 e 2017.

\begin{tabular}{|c|c|c|c|}
\hline \multirow[t]{2}{*}{ REGIÃO } & \multicolumn{3}{|c|}{ TOTAL DE ACIDENTES } \\
\hline & 2015 & 2016 & 2017 \\
\hline BRASIL & 38.926 & 33.063 & 26.959 \\
\hline NORTE & 3350 & 2490 & 1778 \\
\hline ACRE & 121 & 74 & 84 \\
\hline AMAPÁ & 49 & 55 & 47 \\
\hline AMAZONAS & 460 & 395 & 314 \\
\hline PARÁ & 1716 & 1303 & 917 \\
\hline RONDÔNIA & 751 & 374 & 180 \\
\hline RORAIMA & 96 & 91 & 86 \\
\hline TOCANTINS & 157 & 198 & 150 \\
\hline NORDESTE & 6168 & 5346 & 4456 \\
\hline ALAGOAS & 294 & 237 & 172 \\
\hline BAHIA & 1708 & 1285 & 1333 \\
\hline CEARÁ & 953 & 942 & 718 \\
\hline MARANHÃO & 620 & 625 & 481 \\
\hline PARAÍBA & 354 & 297 & 242 \\
\hline PERNAMBUCO & 1198 & 1018 & 847 \\
\hline PIAUÍ & 350 & 439 & 268 \\
\hline RIO GRANDE DO NORTE & 453 & 328 & 275 \\
\hline SERGIPE & 238 & 175 & 120 \\
\hline SUDESTE & 20305 & 16868 & 13373 \\
\hline ESPÍRITO SANTO & 836 & 623 & 525 \\
\hline MINAS GERAIS & 4271 & 3422 & 2893 \\
\hline RIO DE JANEIRO & 4304 & 3232 & 2001 \\
\hline SÃO PAULO & 10894 & 9591 & 7954 \\
\hline SUL & 6184 & 5631 & 5031 \\
\hline PARANÁ & 2515 & 2256 & 2077 \\
\hline RIO GRANDE DO SUL & 2053 & 1775 & 1512 \\
\hline SANTA CATARINA & 1616 & 1600 & 1442 \\
\hline CENTRO-OESTE & 2919 & 2728 & 2321 \\
\hline DISTRITO FEDERAL & 555 & 533 & 499 \\
\hline GOIÁS & 963 & 1031 & 844 \\
\hline MATO GROSSO & 962 & 683 & 531 \\
\hline MATO GROSSO DO SUL & 439 & 481 & 447 \\
\hline
\end{tabular}

Fonte: Ministério da fazenda (2017).

O comparativo dos dados referentes a evolução dos acidentes de trabalho no tempo está exposto no gráfico 1.

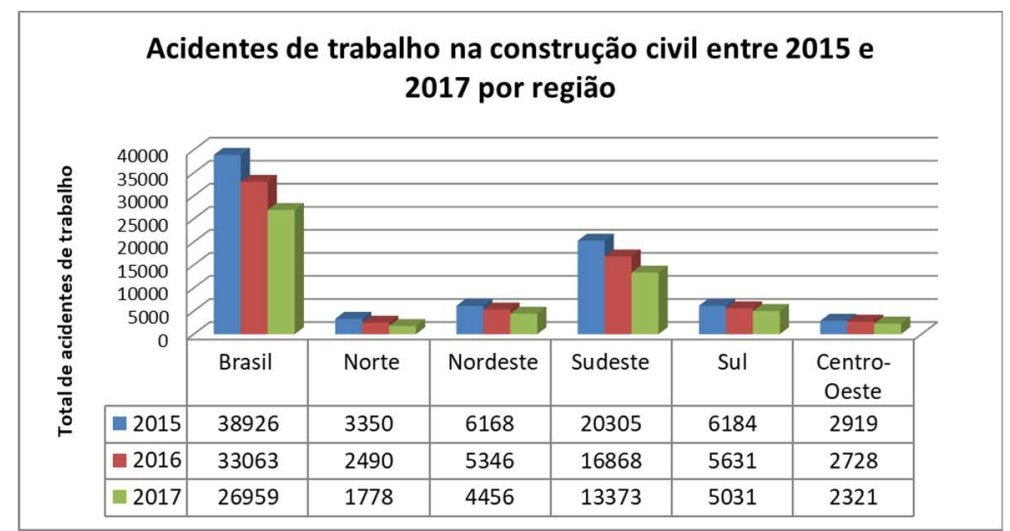

Gráfico 1: Total de acidentes de trabalho na construção civil por região entre 2015 e 2017. Fonte: Ministério da fazenda (2017).

Ao observar estes dados pode-se notar um decréscimo nos acidentes de trabalho relacionados à construção civil em todas as regiões. É importante destacar que ao longo destes anos a região sudeste, 
localidade mais populosa, urbanizada e industrializada do país, foi a que apresentou maiores índices de acidentes, seguidos pela região Sul e Nordeste, enquanto as regiões Norte e Centro-Oeste apresentaram os menores índices.

É na região sudeste que ocorrem praticamente metade de todos acidentes de trabalho na construção civil, e isso se deve ao fato de possuir grandes polos geradores de emprego e, consequentemente, maior quantidade de obras.

Observando os dados da região Norte, nota-se que a mesma apresentou pouca contribuição para o total de acidentes de trabalho no Brasil, sendo a porcentagem de 2015 de 8,6\%, em 2016 foi de 7,5\% e em 2017 de 6,6\%, seguindo a tendência de decréscimo observada nas demais regiões consequência de um desaquecimento generalizado na atividade econômica no país.

Segundo dados do IBGE (Instituto Brasileiro de Geografia e Estatística) as empresas ativas no setor da construção civil, reduziram de 131.318 em 2015 para 126.316 em 2017, foram fechadas nesse período 5.002 empresas. Entre outros fatores, essa baixa contribuição da região Norte no total de acidentes, está associada ao baixo desenvolvimento do setor da construção civil na região Norte quando comparada às demais regiões brasileiras.

Conforme dados do IBGE, em 2017 no Brasil eram 126.316 empresas ativas no setor da construção civil e a região norte contava com a menor quantidade, apenas 3.726 empresas, cerca de 2,9\% do total. Já na região sudeste estavam localizadas 63.865 praticamente a metade das empresas.

Ao analisar o quantitativo de acidentes de trabalho no estado do Tocantins, pode-se afirmar que os números são consideravelmente baixos, porém não sofreu decréscimos sucessivos, visto que subiu de 157 casos em 2015 para 198 casos em 2016, um aumento de 41 casos, ou seja um aumento de aproximadamente 26\% em relação ao ano anterior; para depois, no ano de 2017, reduzir-se abaixo dos números de 2015, para 150 casos, ou seja uma redução de aproximadamente 24\% se comparada com 2016.

A contribuição do Tocantins no total de acidentes no Brasil, é uma das menores do país. $O$ estado ocupou em 2015 a 24 posição e a 23o posição nos anos de 2016 e 2017, ficando na frente apenas de Sergipe, Roraima, Acre e Amapá, sendo que destes estados somente o Sergipe não pertence a região Norte.

$\mathrm{Na}$ região Norte os estados que mais contribuem com o percentual de acidentes, são respectivamente: Pará, Amazonas, Rondônia, Tocantins, Roraima, Acre e Amapá, logo o Tocantins ocupa a 4ㅇ posição, entre os sete estados que integram a região norte.

A indústria da construção civil representa um dos segmentos da economia que absorve um percentual grande de mão de obra, sobretudo por se tratar de um setor que, historicamente no Brasil, emprega profissionais com baixa escolaridade e qualificação, e cujos processos produtivos são arcaicos com baixo usos de tecnologia, pouca mecanização, além de um processo descontínuo, dada a mobilização e desmobilização dos profissionais a cada obra executada. Tais fatores são grandes causadores de acidentes, comprometendo a integridade física dos trabalhadores (TAKAHASHI et al., 2012).

O gráfico 2 mostra a quantidade de pessoal ocupado em 31/12 na indústria da construção civil, nas regiões brasileiras entre os anos de 2015 e 2017, segundo informações retirados do site do IBGE (Instituto 
Brasileiro de Geografia e Estatística), coletados com a pesquisa PAIC (Pesquisa Anual da Indústria da Construção).

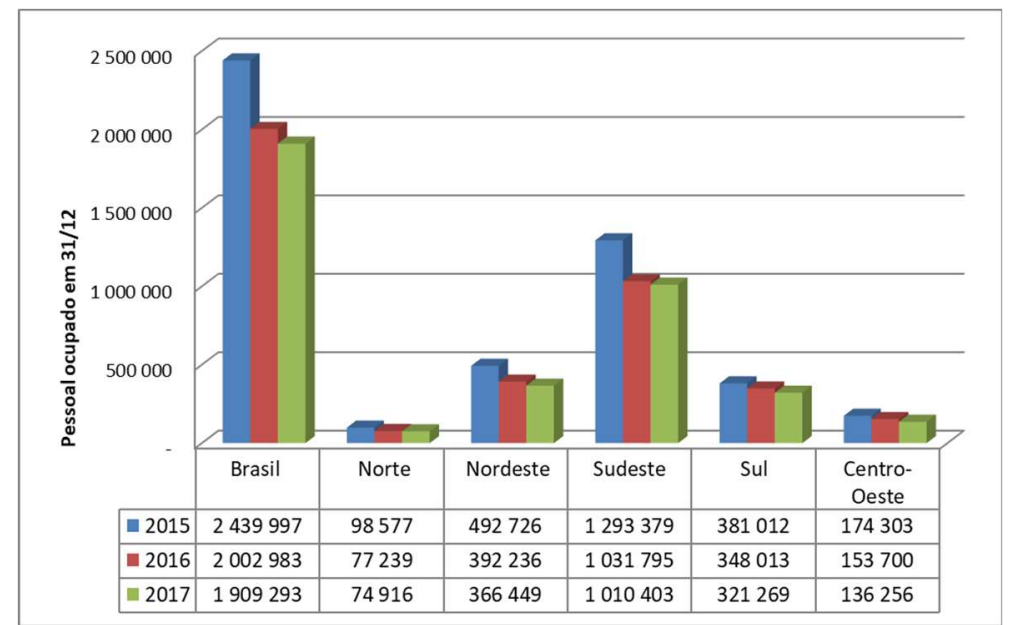

Gráfico 2: Pessoal ocupado em 31/12 na construção civil por região entre 2015 e 2017. Fonte: IBGE (2017).

Ao analisar o gráfico 02 nota-se que a região com mais trabalhadores na indústria da construção civil é a região sudeste, seguidas pelas regiões nordeste e sul que estão intermediárias e com menor participação as regiões Centro Oeste e Norte.

Observa-se que a quantidade de empresas ativas e de pessoal ocupado na indústria da construção também reduziu ao longo dos anos, acompanhando a redução dos acidentes. Entre 2015 e 2017 no Brasil houve uma redução de mais de meio milhão (530.704) de pessoas ocupadas, o que demonstra uma grande baixa na construção civil.

Segundo Santos et al. (2018) a crise econômica presente nos últimos anos trouxe grandes impactos no mercado de trabalho. No período de abril de 2015 a janeiro de 2017, houve no Brasil consecutivas perdas de contratos de trabalho formal, aproximadamente 3 milhões de pessoas teve baixa na sua carteira de trabalho, conforme dados do CAGED (Cadastro Geral de Empregados e Desempregados). Entre 2015 e 2016 houve uma queda de 7\% do PIB, Produto Interno Bruto, que associado à instabilidade política-institucional teve como consequências algumas mudanças na lei trabalhista, muitas prejudiciais a oferta de trabalho.

Ao comparar o gráfico 1 e o gráfico 2, ou seja, a quantidade de acidentes de trabalho e a quantidade de pessoal ocupado na indústria da construção civil, nota-se que quanto maior a quantidade de trabalhadores ativos, maior a quantidade de acidentes, logo essa é uma variante que tem grande influência no total de acidentes de trabalho.

Analisando está proporcionalidade entre a quantidade de acidentes e de pessoal ocupado, verificase que em 2015 e 2016 no Brasil, a porcentagem de acidentes em relação a quantidade de trabalhadores ativos na construção civil, foi em torno de 1,6\% e em 2017 este percentual reduziu para 1,4\%.

SESI (2013) menciona que no Brasil a cada 10.000 trabalhadores da indústria da construção, ocorrem 2 mortes e 920 casos de acidentes de trabalho não fatais por ano, sendo que apenas 74 desses casos serão encaminhados para receber benefício do INSS de forma temporária ou permanente. Isso mostra o quanto é frequente os acidentes envolvendo os trabalhadores da construção civil, acidentes esses que muitas vezes 
nem entram nas estatísticas oficiais.

Segundo Barbosa Filho (2015), os acidentes fatais e ferimentos graves deste setor tem como origem, em grande parte, um grupo seleto de causas: queda em altura, soterramento, choque elétrico e choque ou impacto mecânico.

Além desta diminuição na quantidade de trabalhadores ativos na construção civil, outras causas também podem estar relacionadas com essa redução da quantidade de acidentes, como por exemplo, a maior informação dos profissionais acerca dos equipamentos e medidas de segurança, o maior investimento dos empregadores em técnicas de segurança do trabalho, maior aplicação das normas de segurança e entre outros fatores.

Para Almeida et al. (2018) mesmo com a constante implantação de mudanças nos canteiros de obras e da intensa fiscalização para cumprimento das normas regulamentadoras e das leis trabalhistas, o setor da construção civil ainda apresenta elevados casos de acidentes de trabalho.

Pampalon (2019) destaca algumas características da construção civil que dificultam o gerenciamento dos riscos destes empreendimentos, colaborando com o aumento dos acidentes de trabalho. Como por exemplo, a baixa qualificação da mão de obra; indústria nômade; cada obra é única; há grandes volumes de insumos; têm baixo grau de precisão comparado com outros segmentos; apresenta grande inércia às inovações; realiza trabalhos expostos às intempéries e devido ao cronograma sofre com a pressão do tempo.

Segundo Peinado (2019) à frente de serviço que apresenta maior quantidade de acidentes de trabalho na indústria da construção civil é a construção de edifícios, em segundo lugar estão as obras para geração e distribuição de energia elétrica e telecomunicações, e em terceiro a incorporação de empreendimentos imobiliários.

Segundo Almeida et al. (2018) para contribuir com a segurança dos trabalhadores algumas medidas preventivas podem ser realizadas, como por exemplo:

Implantação de um bom planejamento da obra; a realização de treinamentos e palestras; o investimento em profissionais especializados em segurança do trabalho; a manutenção preventiva dos equipamentos de proteção e a utilização dos mesmos; o estudo e aplicação rigoroso das Normas Regulamentadoras e o Diálogo Diário de Segurança (DDS), uma vez que realizar o diálogo é uma ótima maneira de se trocar experiências entre empregado, empregador e profissionais de saúde, de modo a mapear os riscos e neutralizá-los. (ALMEIDA et al., 2018)

Carvalho (2014) verificou que os trabalhadores em geral sofrem com a falta de informação e/ou formação, visto que a maioria não tem consciência dos riscos aos quais estão suscetíveis diariamente no ambiente de trabalho. Estes riscos podem estar associados ao tipo do trabalho, às práticas de trabalho individuais, à falta de conhecimento, e à pressão devido às restrições orçamentais, tempo e outras.

Segundo Gomes et al. (2017) orientar empregadores e empregados quanto aos procedimentos adequados no processo de produção, trabalhando com a prevenção, gera uma cultura de segurança, que aumenta a qualidade de vida no ambiente de trabalho, e reduz significativamente os acidentes e doenças ocupacionais.

Pensando nisso foi elaborado uma cartilha informativa e preventiva específica para os trabalhadores 
da construção civil, a fim de contribuir com a segurança dos trabalhadores e conscientizá-los da importância de seguir as recomendações de prevenção.

A cartilha está disponível nos anexos deste artigo, e disponível para download ${ }^{3}$ e foi elaborada com o auxílio da Norma Regulamentadora 06, Borges et al. (2019) e SESI (2008).

\section{CONCLUSÕES}

O setor da construção civil tem grande contribuição para o elevado índice de acidentes de trabalho, tal fato se deve, entre outros fatores, às características peculiares destes empreendimentos, como o local de trabalho temporário e baixa qualificação da mão de obra; aos variados riscos que os trabalhadores estão expostos, como ruídos e produtos químicos; ou simplesmente pela imprudência dos trabalhadores ou das empresas que negligenciam a legislação quanto a prevenção destes acidentes.

A consequência desta negligência é desastrosa e atinge vários setores, desde os trabalhadores e sua família até o poder público pelo sistema previdenciário, por isso é preciso que as empresas invistam em medidas de segurança a fim de evitar ou diminuir estes acidentes.

No Brasil o setor da construção civil vem diminuindo os números de acidentes de trabalho entre 2015 e 2017. Com a análise e correlação dos dados pode-se concluir que dentre as principais causas desta redução na quantidade de acidentes, está a grande baixa do mercado de trabalho na construção civil, que teve como consequência a desocupação de muitos trabalhadores.

Outros fatores também podem ter contribuído para isso, como a implantação de mudanças na organização dos canteiros de obras e a intensificação de fiscalizações, com o cumprimento de leis e normas regulamentadoras.

Mesmo com estes decréscimos sucessivos tais índices ainda são bastante significativos, merecendo a atenção por parte de todos os envolvidos. Pois é evidente que um acidente de trabalho não é decorrente de apenas uma causa e sim de uma sequência de erros durante as etapas de uma obra, que vai desde o planejamento até a entrega final da obra, como falhas nos materiais, máquinas, local, equipamentos, organização, trabalhador, influências externas e internas, fiscalização, e muitas outras circunstâncias.

Logo, é necessário que o estado cumpra sua função de fiscalização e normatização das medidas de segurança, e que os empregadores e empregados cumpram as normas regulamentadoras. Deve-se investir na formação dos gestores, engenheiros e mestres de obras, bem como no comprometimento da direção, a fim de implantar ações de segurança claras e objetivas que preservem a saúde física e mental dos seus colaboradores.

\section{REFERÊNCIAS}

ALMEIDA, A. G.; SILVA, L. A.; BERTEQUINI, A. B. T.. A segurança do trabalho na construção civil. In: ENPEX ENSINO, PESQUISA E EXTENSÃO, 18. Anais. Unitoledo, 2018. p.1-17.
BARBOSA FILHO, A. N.. Segurança do trabalho na construção civil. São Paulo: Atlas, 2015.

BORGES, M. C.; PEINADO, H. S.. Equipamentos de Proteção Coletiva: Especificações técnicas e diretrizes de projeto. In:

\footnotetext{
${ }^{3}$ https://bit.ly/3958Yp2
} 
PEINADO, H. S.. Segurança e saúde do trabalho na indústria da construção civil. São Carlos: Scienza, 2019. p.109-152.

CARVALHO, A. R. M.. A falta de formação e qualificação como fatores de risco: as suas implicações na segurança do trabalho. Dissertação (Mestrado em Sistemas Integrados de Gestão Qualidade, Ambiente e Segurança) - Instituto Politécnico do Cávado e Ave, Barcelos, 2014.

GOMES, M. E. M. F.; BARBOSA, A. F. B.. Sistema de gestão integrada na construção civil. Revista de Engenharia e Pesquisa Aplicada, v.2, n. 2, p.1-6, 2017. DOI: https://dx.doi.org/10.25286/repa.v2i2.542

IBGE. Instituto Brasileiro de Geografia e Estatística. Pesquisa Anual da Indústria da Construção. Brasília: IBGE, 2017.

MF. Ministério da Fazenda. Anuário Estatístico de Acidentes do Trabalho: AEAT 2017. Brasília: MF, 2017.

MTE. Ministério do Trabalho e Emprego. NR 06: Equipamento De Proteção Individual: EPI. Brasília: Ministério do Trabalho e Emprego, 1978.

PAMPALON, G.. Gestão do trabalho em altura na construção civil. Brasília: CBIC, 2019.
PEINADO, H. S.. Segurança e saúde do trabalho na indústria da construção civil. In: PEINADO, H. S.. Segurança e saúde do trabalho na indústria da construção civil. São Carlos: Scienza, 2019. p.29-84.

SANTOS, L.; ARUTO, P. C.. Impactos da crise econômica no mercado de trabalho catarinense: uma análise do triênio 2015-2017. Revista NECAT, v.7, n.13, p.53-71, 2018.

SESI. Serviço Social da Indústria. Manual de segurança e saúde no trabalho: Indústria da Construção Civil: Edificações. São Paulo: SESI, 2008.

SESI. Serviço Social da Indústria. Segurança e saúde na Indústria da construção no Brasil: diagnóstico e recomendações para a prevenção dos acidentes de trabalho. Programa Nacional de Segurança e Saúde no Trabalho para a Indústria da Construção, Brasília: SESI, 2013.

TAKAHASHI, M. A. B. C.; SILVA, R. C.; LACORTE, L. E. C.; CEVERNY, G, C. O.; VILELA, R. A. G.. Precarização do Trabalho e Risco de Acidentes na construção civil: um estudo com base na Análise Coletiva do Trabalho (ACT). Saúde Soc., São Paulo, v.21, n.4, p.976-988, 2012. DOI: https://doi.org/10.1590/S0104-12902012000400015

A CBPC - Companhia Brasileira de Produção Científica (CNPJ: 11.221.422/0001-03) detém os direitos materiais desta publicação. Os direitos referem-se à publicação do trabalho em qualquer parte do mundo, incluindo os direitos às renovações, expansões e disseminações da contribuição, bem como outros direitos subsidiários. Todos os trabalhos publicados eletronicamente poderão posteriormente ser publicados em coletâneas impressas sob coordenação da Sustenere Publishing, da Companhia Brasileira de Produção Científica e seus parceiros autorizados. Os (as) autores (as) preservam os direitos autorais, mas não tem permissão para a publicação da contribuição em outro meio, impresso ou digital, em português ou em tradução. 